\title{
The life cycle of Huffmanela huffmani Moravec, 1987 (Nematoda: Trichosomoididae), an endemic marine-relict parasite of Centrarchidae from a Central Texas spring
}

\author{
McLean L. D. Worsham ${ }^{1}$, David G. Huffman ${ }^{1}$, František Moravec $^{2}$ and J. Randy Gibson ${ }^{3}$ \\ ${ }^{1}$ Freeman Aquatic Biology, Texas State University, San Marcos, TX, USA; \\ ${ }^{2}$ Institute of Parasitology, Biology Centre of the Czech Academy of Sciences, České Budějovice, Czech Republic; \\ ${ }^{3}$ U.S. Fish and Wildlife Service, Aquatic Resources Center, San Marcos, TX, USA
}

\begin{abstract}
The life cycle of the swim bladder nematode Huffmanela huffmani Moravec, 1987 (Trichinelloidea: Trichosomoididae), an endemic parasite of centrarchid fishes in the upper spring run of the San Marcos River in Hays County, Texas, USA, was experimentally completed. The amphipods Hyalella cf. azteca (Saussure), Hyalella sp. and Gammarus sp. were successfully infected with larvated eggs of Huffmanela huffmani. After ingestion of eggs of $H$. huffmani by experimental amphipods, the first-stage larvae hatch from their eggshells and penetrate through the digestive tract to the hemocoel of the amphipod. Within about 5 days in the hemocoel of the experimental amphipods at $22^{\circ} \mathrm{C}$, the larvae presumably attained the second larval stage and were infective for the experimental centrarchid definitive hosts, Lepomis spp. The minimum incubation period before adult nematodes began laying eggs in the swim bladders of the definitive hosts was found to be about 7.5 months at $22{ }^{\circ} \mathrm{C}$. This is the first experimentally completed life cycle within the Huffmanelinae.
\end{abstract}

Keywords: swim bladder nematode, Trichinelloidea, development, intermediate host, Amphipoda, Hyalella, Gammarus, fish, USA

Adult trichinelloid nematodes occur in a wide range of vertebrate hosts. The vast majority of species infect epithelial surfaces, although a few species infect spleen or liver tissues, or are found in other tissues (Anderson 2000, Anderson et al. 2009). Although the development and transmission of some species with medical importance or those parasitising economically significant groups of animal hosts have been extensively studied (for reviews see Moravec et al. 1987, Anderson 2000, Moravec 2001), the biology of trichinelloids as a whole still remains little known. Aside from well-studied trichinelloid taxa, little else is known about the morphogenesis of larvae during development or the life cycle patterns for the vast majority of trichinelloid species. This is particularly true regarding whether or not an intermediate host is required (Moravec 2001).

Most of the data available on the life cycles of trichinelloids pertains to representatives of the species-rich family Capillariidae Railliet, 1915, whereas information on the life cycles of representative of other trichinelloid families is rather scarce or absent (Anderson 2000). Within the Trichosomoididae (apparently closely related to Capillariidae), only the life cycle of Trichosomoides crassicauda (Bellingham, 1840) from the urinary tract of rats has been studied in detail (e.g. Löwenstein 1910, Thomas 1924, Wahl and Chapman 1967, Hasslinger and Schwarzler 1980). The eggs of this nematode were directly infective to the definitive host. To date, very little has been reported about the life cycles of representatives of the trichosomoidid genus Trichuroides Ricci, 1949 (T. chiropteri Ricci, 1949 from the urinary bladder of bats), or of the numerous species of Huffmanela Moravec, 1987 parasitising fishes.

Huffmanela huffmani Moravec, 1987 (Trichinelloidea: Trichosomoididae: Huffmanelinae) is a parasitic nematode known only from the swim bladders of centrarchid fishes from the upper spring run of the San Marcos River (SMR) in Hays County, Texas (29 $53^{\prime} 36^{\prime \prime} \mathrm{N}$; 97 $\left.97^{\circ} 52^{\prime \prime} \mathrm{W}\right)$. The first reported occurrence of $H$. huffmani was in 1979, when Underwood and Dronen (1984) reported eggs from the swim bladders of various centrarchids in the SMR and identified the eggs as representing an unidentified species of Capillaria Zeder, 1800. The species was later formally described as Huffmanela huffmani based on eggs alone (Moravec 1987) and the new genus Huffmanela was erected to accommodate it. Adults of the species were subsequently described by Huffman and Moravec (1988). The description of $H$. huffmani preceded the reassignment of several species from Capillaria into the genus Huffmanela, 
Table 1. Akaike information criterion contrast coefficients and feeding-niche categories of centrarchid species from San Marcos Springs based on observed foraging behavior. The contrast coefficients reflect relative likelihood that fish in the category could be expected to encouter and consume benthic, spring-related, detritivorous invertebrates.

\begin{tabular}{lll}
\hline Contrast coefficient & Category definition & Example taxon \\
\hline 0 & Non-centrarchid & Herichthys cyanoguttatus Baird et Girard \\
1 & Limnetic/zooplanktivorous & Lepomis macrochirus Rafinesque \\
2 & Littoral/invertivorous & Lepomis miniatus Jordan \\
3 & Benthic/invertivorous & Lepomis microlophus Günther \\
4 & Spring-dominant benthic/invertivorous & Lepomis auritus Linnaeus \\
\hline
\end{tabular}

as well as the erection of Huffmanelinae Moravec, 2001 by Moravec (2001).

Some twenty other species of Huffmanela are now documented, all of which are histozoic in marine fishes from coastal and blue-water habitats of diverse geographic regions across the world's oceans (Ruiz et al. 2013, Justine and Iwaki 2014). Since all species of Huffmanela other than $H$. huffmani are marine, it is likely that $H$. huffmani is a marine relict. This assertion is consistent with the presence of numerous other marine-relict invertebrates unique to the San Marcos Springs (SMS) (Holsinger and Longley 1980). Furthermore, even though many invertebrate taxa that are not marine relicts are also restricted to just the spring-influenced Upper SMR, none of the SMR marine relicts are found outside of a subterranean or spring-confined distribution (Gibson et al. 2008). Much like the other SMR invertebrates of marine taxonomic affiliations, reports from previous surveys have indicated that $H$. huffmani is also restricted to just the spring-influenced Upper SMR (Michel 1984, Cox et al. 2004, O’Docharty 2007). These findings are consistent with the hypothesis that $H$. huffmani is a marine relict with a spring-associated distribution.

The majority of the species of Huffmanela are described from eggs alone, with adults having been described thus far from only six species (Bullard et al. 2012). Each species of Huffmanela deposits its eggs in a species-specific organ of its definitive host. However, aside from the location of egg deposition, little else is known about any of the life cycles of Huffmanela spp. The location of egg deposition by H. huffmani (and many other Huffmanela spp. that are histozoic in internal organs of the definitive host) is remarkable because eggs cannot be released from a living definitive host to infect the next host. Previous research has been unable to get ingested eggs of $H$. huffmani to hatch inside the definitive host (Cox 1998, Moravec 2001, Cox et al. 2004, O'Docharty 2007); therefore, an infected definitive host laden with eggs of $H$. huffmani must be decomposed or digested in order for the eggs to become available to the presumptive intermediate host.

Eggs of $H$. huffmani are appreciably denser than water, and once liberated from the host, they ultimately come to rest on the benthic sediments. Because eggs cannot infect fish directly and because eggs are found only among the benthos once outside the definitive host, it has been suggested that a benthic detritivore must be serving as the intermediate host (Cox et al. 2004, O’Docharty 2007). Therefore, the first step in solving the life cycle of $H$. huffmani was to determine if there is, in fact, an intermediate host, and if so, to identify that host and use it to experimentally complete the life cycle. Presented herein is the experimentally completed life cycle of $H$. huffmani; the first described for any of the about 20 known species of the Huffmanelinae.

\section{MATERIALS AND METHODS}

\section{Analysis of habitat preferenda of definitive hosts to suggest intermediate hosts}

Initially, centrarchids foraging around spring openings in Spring Lake (the impounded headsprings of the SMR) were periodically observed, photographed and videographed by divers during both day and night, from January through May of 2012, inclusively. After determining the preferred feeding habitats of the centrarchid species known to be susceptible to $H$. huffmani (Moravec et al. 1987, O’Docharty 2007), each species was assigned to one of four feeding-niche categories. Because the presumptive intermediate host was suspected of being a benthic, spring-dependent, detritivorous invertebrate, we were able to use these category assignments to rank the centrarchid species by how frequently they would be expected to encounter and consume such invertebrates. These species are listed in Table 1 along with their feeding-niche categories and respective contrast coefficients.

Following the feeding preferendum analysis, centrarchids were collected from Spring Lake and necropsied in order to determine if the actual levels of parasitism for each species corresponded to the expectations that emerged from the feeding preferendum analysis. These survey fish were collected by angling with artificial lures and transported back to the laboratory in at least 101 of spring water. Because it was not known if eggs of $H$. huffmani are environmentally sensitive, and one of the goals of fish collections was to obtain viable eggs, transport of fish back to the laboratory was expedited in order to ensure that dissolved oxygen and temperature did not deviate substantially from optimal conditions potentially required by $H$. huffmani. Fish were then transferred to a tank supplied with flowing, untreated artesian well water physicochemically similar to SMS water in most measurable parameters. The fish were maintained at $22^{\circ} \mathrm{C}$ under a 12/12 h light/dark cycle until just before necropsy.

Fish were killed by pithing and the swim bladder was excised. A small portion of the epithelium of the ventral wall of the swim bladder was separated from the remainder of the swim bladder and was used to roughly estimate the intensity of infection using compound light microscopy at $40 \times$ to $200 \times$ magnification. Because a single swim bladder might contain a million or more eggs (Cox 1998), intensity was not determined by counts, but was estimated by the approximate percentage of the visual field where 
Table 2. Descriptions of infection-intensity categories used to estimate the intensity of infection with eggs of Huffmanela huffmani Moravec, 1987 in the ventral wall of the swim bladders of wild-caught centrarchids.

\begin{tabular}{ll}
\hline $\begin{array}{l}\text { Infection- } \\
\text { intensity } \\
\text { category }\end{array}$ & Description \\
\hline 0 & no eggs detected \\
1 & trace infection; only a few eggs observed \\
2 & up to $25 \%$ of swim bladder infected with eggs \\
3 & greater than $25 \%$ and up to $50 \%$ of swim bladder infected \\
4 & greater than $50 \%$ of swim bladder infected \\
\hline
\end{tabular}

eggs had been deposited. These intensity estimates were broken out into five infection-intensity categories as defined in Table 2.

The remaining tissue of each swim bladder was placed individually into a sealed $700 \mathrm{ml}$ plastic food container filled with artesian water. These containers were maintained in a water bath of flowing artesian water to maintain a constant temperature of $22^{\circ} \mathrm{C}$ (similar to the SMS water) while microbial decay was allowed to break down swim bladder tissues and free the eggs. Water in these containers was refreshed twice monthly.

Using the infection-intensity data derived from the wildcaught fish, an Akaike information criterion (AIC) analysis was performed to determine the factors that best predicted the observed intensity ratings of the wild-caught fish. This analysis used three one-way ANOVAs (alpha $=0.01$ ) employing host standard length, the contrast coefficients mentioned above (Table 1), and species as predictors of the intensity ratings observed for these fish. The factor 'standard length' was used as a predictor to assess whether or not there was a minimum size at which the fish could be expected to be positive for eggs of $H$. huffmani. If so, it could indicate that something is preventing the fish from consuming infected invertebrates until the fish reach a certain minimum size. This, in turn, could have potentially provided useful hints about the intermediate host. The factor 'species' was used as a predictor to assess whether or not species-related differences in the susceptibility to $H$. huffmani could explain differences in the infection-intensity ratings. The factor 'contrast coefficients' was used as a predictor to assess if observed differences in the prevalence and intensity rating could best be explained by feeding niche of the definitive host.

\section{Selection of candidate intermediate hosts}

At the time of this writing, approximately 200 species of macroinvertebrates have been reported from the SMS and SMR (Edwards and Arnold 1961, Bowles et al. 2007, Gibson et al. 2008, Diaz and Alexander 2010), most of which are benthic. To narrow down the most promising candidate species from this list, literature discussing the life cycles of related fish nematodes in the Trichinelloidea was reviewed (Moravec et al. 1998, Køie and Nylund 2001). Based on that review, the intermediate host for H. huffmani was suspected of being either an annelid or an amphipod. This conclusion complicated our life-cycle investigations, as there are at least 13 species of amphipods known to occur locally (Holsinger and Longley 1980, Gibson et al. 2008) and since the literature on the annelids of the SMR was almost non-existent. Therefore, it became necessary to survey the annelids of SMS, which was found to contain at least 20 benthic species, including at least 16 species of oligochaetes, 2 aphanoneurans and 3 leeches (Worsham et al. 2016).

Benthic invertebrates were collected from near spring openings using a Ponar grab sampler. Individual collections were transported back to the laboratory in separate containers of $22^{\circ} \mathrm{C}$ spring water and maintained alive until sorted. The organisms were examined under a dissecting microscope and sorted into containers representing the lowest discernable taxon. From these collections, live cultures of candidate intermediate hosts were established and maintained in the laboratory in labelled $1200 \mathrm{ml}$ plastic food containers with windows cut in the sides and covered with $200 \mu \mathrm{m}$ mesh. These culture containers were floated in a flow-through system of artesian water to ensure constant physicochemical conditions similar to the SMS.

Selection of candidate intermediate hosts was based on the notion that the intermediate host must be abundant enough to account for the high prevalence of infection we observed, and also the assumption that the intermediate host is a benthic species. Since the hypothetical intermediate host was also presumed to be a detritivore, only benthic species that could be maintained on a diet of detritus were used in experimental infection attempts.

\section{Testing of candidate intermediate hosts for susceptibility}

Candidate invertebrate species were tested for susceptibility to infection with $H$. huffmani by placing them in a container with an aliquot of larvated and viable eggs. Controls were maintained in the same way, but without exposure to eggs of H. huffmani. All invertebrate exposures were run for two weeks, or until all treatment specimens had died, whichever occurred first. If the rate of population decline in the treatment containers began to exceed the rate of decline in the corresponding controls by a noticeable margin, all individuals in both groups were examined immediately for larvae of $H$. huffmani. At the end of the two weeks, all remaining experimental subjects were examined for larvae. When nematode larvae were discovered among the treatment replicates of a species, the associated controls were also examined to assure that they were negative. A list of the taxa tested for susceptibility to $H$. huffmani is provided in Table 3 .

Of all the invertebrate taxa we attempted to infect, only the talitroid amphipods of the genus Hyalella Smith and freshwater gammarideans of the genus Gammarus Linnaeus became infected. All Hyalella spp. tested for susceptibility showed evidence of larvae outside the gut lumen (no lumenal or extralumenal nematode larvae were found in the control Hyalella).

Subsequent methods pertaining to the intermediate hosts of H. huffmani employed amphipods belonging to two presumptive species of Hyalella. One species is a common and widely distributed species in the Hyalella cf. azteca (Saussure) eco-morph complex, while the other is an undescribed species endemic to the SMS. All amphipods used in the experiments that follow were $\mathrm{F}_{1}$ or later generations raised in artesian water in the laboratory.

\section{Graded exposure of candidate intermediate hosts and expo- sure of definitive host}

\section{Titration of amphipod exposure intensity}

In an attempt to determine effective dosage regimens of eggs that would most likely produce detectable infections in amphipods without killing them, amphipods were subjected to larvated eggs 
Table 3. List of invertebrate taxa exposed to eggs of Huffmanela huffmani Moravec, 1987.

\begin{tabular}{|c|c|c|}
\hline Higher taxon & Taxon & $\mathrm{n}$ \\
\hline Annelida: Aphanoneura & Aeolosoma spp. (SMR) & 10 \\
\hline Annelida: Clitellata & Chaetogaster diastrophus Baer (SMR) & 10 \\
\hline Annelida: Clitellata & Dero furcatus Müller (SMR) & 5 \\
\hline Annelida: Clitellata & Dero obtusa d'Udekem (SMR) & 10 \\
\hline Annelida: Clitellata & Haplotaxis sp. (SMR) & 2 \\
\hline Annelida: Clitellata & Lumbriculidae gen. sp. 1 (SMR) & 5 \\
\hline Annelida: Clitellata & Lumbriculidae gen. sp. 2 (SMR) & 5 \\
\hline Annelida: Clitellata & Pristina sp. (SMR) & 10 \\
\hline Crustacea: Amphipoda Crangonyctidae & Crangonyx cf. pseudogracilis Bousfield (SMR) & 6 \\
\hline Crustacea: Amphipoda Dogielinotidae & 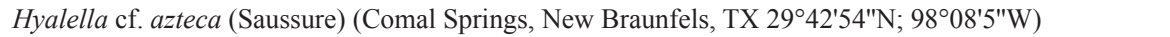 & 10 \\
\hline Crustacea: Amphipoda Dogielinotidae & Hyalella cf. azteca (Finnegan Springs, Devils River drainage 2953'60"N; 10059'53"W) & 10 \\
\hline Crustacea: Amphipoda Dogielinotidae & Hyalella cf. azteca (SMR) & 10 \\
\hline Crustacea: Amphipoda Dogielinotidae & Hyalella sp. (SMS endemic) & 10 \\
\hline Crustacea: Amphipoda Dogielinotidae & $\begin{array}{l}\text { Hyalella texana Stevenson et Peden (Clear Creek Springs, San Saba River drainage, near Menard, TX } \\
\left.30^{\circ} 54^{\prime} 25^{\prime \prime} \mathrm{N} ; 99^{\circ} 57^{\prime} 39^{\prime \prime} \mathrm{W}\right)\end{array}$ & 10 \\
\hline Crustacea: Amphipoda Gammaridae & Gammarus sp. (Caroline Springs, Pecos River drainage, near Sheffield, TX 30²8'09"N; $101^{\circ} 48^{\prime} 12^{\prime \prime} \mathrm{W}$ ) & 3 \\
\hline Crustacea: Amphipoda Crangonyctidae & Stygobromus spp. (SMR) & 6 \\
\hline Crustacea: Copepoda & Cyclopoida Burmeister (SMR) & 10 \\
\hline Crustacea: Isopoda & Cirolanides texensis Benedict (SMR) & 5 \\
\hline Crustacea: Ostracoda & Cypria sp. (SMR) & 10 \\
\hline Crustacea: Ostracoda & Stenocypris sp. (SMR) & 10 \\
\hline Platyhelminthes: Macrostomida & Macrostomida gen. sp. (SMR) & 10 \\
\hline Platyhelminthes: Tricladida & Dugesia sp. (SMR) & 10 \\
\hline Platyhelminthes: Turbellaria & Schmidtea sp. (SMR) & 10 \\
\hline
\end{tabular}

SMR - San Marcos River.

of $H$. huffmani at various combinations of exposure intensity and incubation duration. Amphipods from each species were divided into five groups for the exposure phase, with four of the groups representing four levels of egg-exposure intensity (four durations of exposure to the same density of eggs of $H$. huffmani), and the fifth group serving as a control (not exposed to parasite eggs). Each exposure-intensity group consisted of three replicates, with each replicate housed in a $1200 \mathrm{ml}$ plastic food container.

Prior to distributing amphipods to replicate containers, the 15 marked containers were assigned random numbers, and then arranged in order of increasing random number. Each of the 15 replicate containers received 27 lab-reared amphipods at the beginning of a titration run, for a total of 405 amphipods for one entire run of the titration experiment. Disposable one-piece plastic transfer pipettes with $5 \mathrm{ml}$ capacity (similar to Fisher S30467-1) were used to transfer amphipods individually from container to container. Tips of pipettes were trimmed back along the taper to a larger bore size to allow for easy passage of amphipods.

The process of distributing amphipods from the main culture container to the replicate containers started with selecting one amphipod from the main culture with a transfer pipette and transferring it to the replicate container with the lowest random number. A second amphipod was then transferred to the replicate container with the next lowest random number, and so on, until all replicate containers had been supplied with 27 amphipods. This randomisation procedure was executed in order to ensure that any sequential bias introduced by the amphipod-selection procedure was randomised across treatments. The amphipods were then allowed to habituate to the replicate containers for two days prior to exposure to eggs.

Prior to distribution of eggs of $H$. huffmani into the amphipod containers, eggs were first divided into aliquots using a two-stage randomised serial dilution protocol so as to randomise any se- quential differences in egg concentration across the design. The eggs were first transferred into a container of artesian water. This container was then stirred gently to suspend the eggs, and the suspension was promptly divided among three intermediate dilution containers. Each of these was then stirred and its contents promptly divided among four final-dilution containers, for a total of 12 intermediate containers of relatively equal volume. These 12 containers were then randomly assigned in sets of three to one of four exposure-intensity levels $(12,24,48$ and $96 \mathrm{~h}$ of egg exposure), with the three containers on each level representing treatment replicates.

Following the habituation period, amphipods assigned to the four exposure-intensity levels were simultaneously exposed to eggs of $H$. huffmani from their respective final-dilution containers. The amphipods in exposure-intensity level 1 were examined for larvae of Huffmanela after $12 \mathrm{~h}$, exposure-intensity level 2 after $24 \mathrm{~h}$; exposure-intensity level 3 after $48 \mathrm{~h}$, and exposure-intensity level 4 after $96 \mathrm{~h}$. The amphipods in the fifth group (controls) were not exposed to eggs. The controls were used to determine if any population declines among the corresponding treatment replicates were due to infection with $H$. huffmani (in which case the controls were expected to show a slower decline), or to causes unrelated to egg exposure (with approximately equal decline rates expected).

\section{Titration of minimum prepatent incubation duration}

After the prescribed durations for each level of exposure-intensity had elapsed, amphipods were separated from eggs of Huffmanela and then incubated for varying durations. This was done to estimate the minimum prepatent time after the exposure of an amphipod to eggs before it can become infective to a centrarchid definitive host.

The amphipods were first pipetted individually from their exposure containers and rinsed thoroughly in fresh artesian water 
Table 4. Larval intensity ratings for amphipods exposed to eggs of Huffmanela huffmani Moravec, 1987.

\begin{tabular}{ll}
\hline $\begin{array}{l}\text { Larval intensity } \\
\text { rating of exposed } \\
\text { amphipods }\end{array}$ & Estimated number of larvae \\
\hline 0 & no larvae observed \\
1 & up to 3 larvae \\
2 & 3 or more larvae, but less than 25 \\
3 & 25 or more larvae, but less than approximately 100 \\
4 & approximately 100 or more larvae \\
\hline
\end{tabular}

to ensure removal of eggs of $H$. huffmani. The replicate exposure containers were also rinsed thoroughly. Rinsed amphipods were then placed back into their respective containers for the incubation phase.

All replicate containers at the four exposure-intensity levels showed noticeable population declines, even before rinsing in some cases, whereas the three control replicates showed no declines whatsoever, even after $96 \mathrm{~h}$ of incubation. However, there appeared to be no appreciable difference in amphipod survival among the four exposure-intensity levels, indicating that the maximum exposure-intensity had probably not been exceeded, even at $96 \mathrm{~h}$ of exposure. It was therefore decided to run all subsequent experiments using amphipods exposed to eggs for $96 \mathrm{~h}$.

\section{Examination and feeding-out of exposed amphipods}

At the end of each prescribed incubation duration (following 1, $4,7,14,21,28,35,42$ and 49 days of incubation post-exposure), 3 to 21 amphipods were sampled from each exposure-intensity group, sampling evenly from the three replicate exposure-intensity containers. Each time amphipods were sampled, one of the amphipods was necropsied and closely examined for infection with larvae of $H$. huffmani. The remaining amphipods in each sample were fed out to experimental fish.

After incubation of amphipods for 49 days post-exposure, all infected amphipods from all exposure intensities and incubation durations had either been necropsied, fed out to experimental fish, or had died. None of the control amphipods had died at 49 days, indicating that the treatment amphipods that died had probably died from infection with larvae of $H$. huffmani.

In most cases, exposed amphipods were so heavily infected that exact larval counts were not feasible; therefore, all amphipod infection levels were rated subjectively. The rating codes employed to represent these subjective estimates of amphipod infection intensity are described in Table 4.

\section{Sources of experimental fish}

Experimental centrarchid fish were collected via angling and seining either from the Comal River, where H. huffmani currently does not occur $[0 \%$ prevalence for 120 centrarchids examined by United States Fish and Wildlife Service (USFWS), and all centrarchids examined during three previous studies (Michel 1984, Cox et al. 2004, O’Docharty 2007) were negative], or from captive stock of a leucistic strain of Lepomis cyanellus Rafinesque raised in filtered artesian water at the San Marcos Aquatic Resource Center (SMARC) operated by the U.S. Fish and Wildlife Service. Species represented by wild-caught specimens from the Comal River were Lepomis auritus (Linnaeus), L. miniatus (Jor- dan), L. megalotis (Rafinesque) and L. macrochirus Rafinesque, with the majority being $L$. auritus and L. miniatus.

Experimental fish were maintained at SMARC in cultures of one fish per 32 or 451 aquarium depending on size of fish. Each aquarium received a constant flow-through of Edwards Aquifer well water, and the fish were maintained on commercially available fish food (TetraCichlid Fish Food Sticks), both before and after exposure to infected amphipods.

\section{Exposure and incubation of experimental fish}

For record-keeping purposes, each of the 32 experimental fish was randomly assigned a treatment number representing a unique combination of (1) the number of infected amphipods it had been fed, (2) the incubation duration of the definitive host and (3) the exposure intensity and incubation duration of the amphipods it received. Each amphipod was expected to have several viable larvae in some stage of development at the time it was fed out to fish (most of them probably had $>25$ ). Live amphipods were pipetted individually into the aquaria containing the experimental fish, whereupon the fish were observed to consume all dispensed amphipods.

\section{Examination of experimental fish}

The survey of the literature on other trichosomoidid and capillariid life cycles indicated that the prepatent period before eggs of $H$. huffmani could be expected to appear in the swim bladders of exposed fish would probably be at least 2 months. Thus, the first three exposed fish were scheduled for examination after 3 months of incubation, with three of the remaining exposed fish to be examined each month thereafter.

After fish had been incubated for the prescribed duration, they were pithed and the swim bladder was removed for examination. The entire ventral wall of the swim bladder was cut into small pieces and each piece was mounted under a coverslip in physiological saline. Each piece was then examined for later larval stages, adults or eggs of $H$. huffmani under a compound microscope at $40 \times$ to $100 \times$ magnification.

\section{Completion of life cycle}

$\mathrm{F}_{1}$ eggs of $H$. huffmani from the swim bladder tissues of experimentally infected fish were liberated via microbial decay as described above. Liberated $F_{1}$ eggs were then fed out to laboratory-reared amphipods to verify that the eggs were infective, thus completing the life cycle.

\section{Review of the relationship between definitive host diet and} organ of egg deposition for all reported species of Huffmanela

The organ of egg deposition in the definitive hosts for the various Huffmanela spp., as well as information regarding the diet and habitat preference of the host species, were gathered from the available literature. Each of the species of Huffmanela was then assigned to one of four cells in a $2 \times 2$ table (Table 5). The cells are defined by two variables, each with two categories: location of the organ in which eggs are deposited (internal vs epithelial) and the general habitat of the definitive host (benthic $v s$ pelagic). The overwhelming majority of species of Huffmanela were classified as laying eggs in an internal tissue of a benthic host. This relationship was then evaluated by comparing the proportion of Huffmanela spp. in only two of the four cells of the table: the 
Table 5. Two-by-two table for assigning known species of Huffmanela to a specific combination of habitat and host diet $v s$ location of egg deposition.

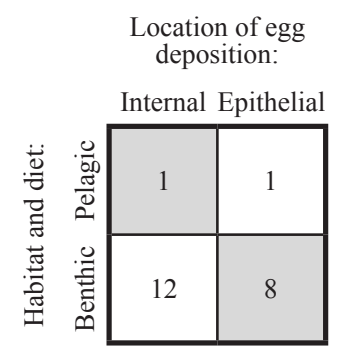

proportion of all species of Huffmanela that deposit eggs in an internal tissue of a benthic definitive host; compared to the proportion of Huffmanela species that deposit eggs in a surface tissue of a pelagic definitive host.

\section{RESULTS}

\section{Analysis of definitive host species to suggest intermediate hosts}

The centrarchid Lepomis auritus is alien to the SMR (TISI 2015) and wild-caught individuals exhibit a high prevalence and high intensity of infection with Huffmanela huffmani (Table 6). Behavioural observations indicated that individual $L$. auritus cooperated with conspecifics to ward off other centrarchid species from their preferred source of food - the benthic invertebrates around spring openings. This spring-dominating behaviour was only displayed by adult $L$. auritus, which also excluded smaller $L$. auritus from the spring openings. The adults of $L$. auritus had a prevalence of $96 \%$ and a mean rating of intensity (as defined above) of $2.8(\mathrm{n}=53)$. Adults of Micropterus salmoides (Lacépède), despite conventional assumption of being top predators, proved to be opportunistic generalists, and were also frequently observed feeding on small benthic spring invertebrates (they were apparently too large to be excluded by L. auritus). Micropterus salmoides was also heavily infected (Table 6).

To evaluate our assumption that the intermediate host of $H$. huffmani is a benthic detritivore, three factors were used to predict infection intensity rating and prevalence. The three factors were fish species, standard length of fish (SL) and assigned feeding-niche category. The niche model was shown to be superior to the other models (Table 7), which is consistent with the intermediate host being a benthic detritivore.

\section{Selection of candidate intermediate hosts}

Of all the invertebrate taxa exposed to eggs of Huffmanela huffmani, only amphipods of the genera Hyalella and Gammarus became infected. All of the Hyalella that were exposed to eggs of $H$. huffmani became infected with larvae of $H$. huffmani, including the Hyalella spp. that do not co-occur with $H$. huffmani in the SMR (Table 3). Only one of the tested species of Hyalella is known to be endemic to the SMS (MLDW - unpubl. data) and therefore probably coevolved with $H$. huffmani. Only three Gammarus
Table 6. Prevalence of infection and mean of intensity rating categories of eggs of Huffmanela huffmani Moravec, 1987 in swim bladders of wild-caught centrarchids from the San Marcos Springs.

\begin{tabular}{lccc}
\hline Species & $\begin{array}{c}\text { Mean of in- } \\
\text { tensity rating } \\
\text { categories }^{1}\end{array}$ & $\begin{array}{c}\text { Prevalence } \\
(\%)\end{array}$ & $\mathrm{n}$ \\
\hline Micropterus salmoides $^{\text {Lepomis auritus }}{ }^{2}$ & 3.00 & 90 & 10 \\
Lepomis miniatus $_{\text {Lepomis microlophus }}$ & 2.64 & 89 & 56 \\
Lepomis macrochirus & 1.83 & 67 & 6 \\
\hline
\end{tabular}

categories as defined in Materials and Methods; ${ }^{2}$ calculated from 53 adults and 3 uninfected juveniles.

Table 7. Akaike information criterion (AIC) weights of competing models used to predict infection intensity ratings of Huffmanela huffmani Moravec, 1987 in wild-caught centrarchids.

\begin{tabular}{lccc}
\hline Model & $F$ ratio & $p$ & AIC weight \\
\hline SL & 8.23 & 0.00581 & 0.0 \\
Species & 9.33 & $6.65^{-07}$ & 0.057 \\
Niche & 48.33 & $4.15^{-09}$ & 0.943 \\
\hline
\end{tabular}

individuals were exposed to eggs of $H$. huffmani; one died, one was lightly infected and the third was uninfected. All subsequent attempts to experimentally infect centrarchids employed the SMS Hyalella and Hyalella cf. azteca as the experimental intermediate hosts.

\section{Exposure of susceptible hosts}

If no amphipods had died during the exposure phase, a total of 36 exposed amphipods would have been available for necropsy on the three examination days (0, 3 and 7 days of exposure). However, because infected amphipods began dying in some of the replicate containers after the examinations had been started; only 30 amphipods were necropsied for infection-intensity rating. The regression slope of infection intensity on exposure duration was not significant.

After larvae had spent 1 week in experimental amphipods, internal development was observed in the larvae (Fig. 1). Although no increase in the length of larvae was observed (larvae were always 270-350 $\mu \mathrm{m}$ long) and no moults were observed (even after 9 weeks of incubation in an amphipod), it can be assumed that they were second-stage larvae. The internal development was not accompanied by a change in the activity level of the larvae. Of the fish that had been fed amphipods containing larvae, only those that had been fed amphipods incubated for at least 5 days post exposure became infected, suggesting the prepatent period in the intermediate host is 5 days and is likely associated with the aforementioned internal development. After this initial duration of incubation in the intermediate host, no difference in infectivity was observed for longer incubation durations.

Dead larvae of $H$. huffmani (Fig. 2) were often observed in some of the experimental amphipods exposed to eggs of $H$. huffmani. Surprisingly, dead larvae were only observed in individuals of the presumably co-evolved endemic SMS 

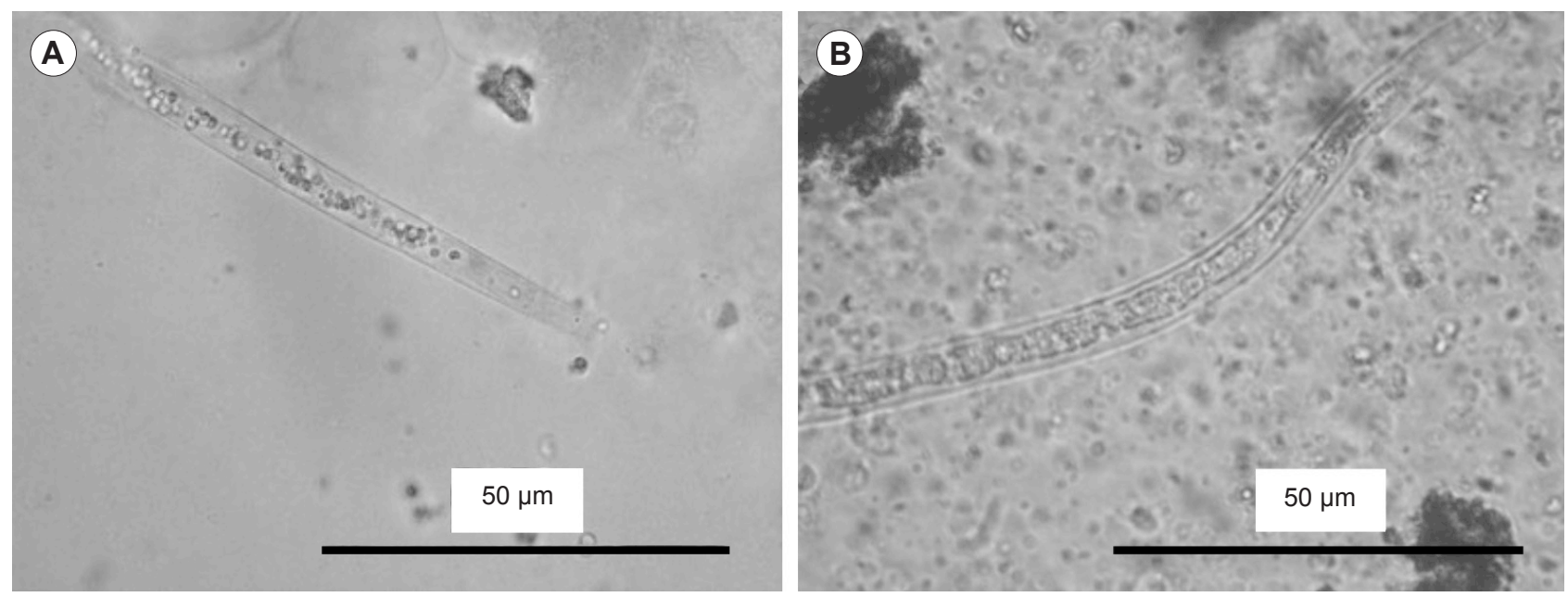

Fig. 1. Naturally hatched larvae of Huffmanela huffmani Moravec, 1987 after being consumed by Hyalella spp. A - a freshly hatched larva containing loose refractile bodies (reserve granules); B - 30 days after hatching, with none of the loose refractile bodies of freshly hatched larvae apparent, but instead, a single condensed central structure is visible throughout the posterior end of the worms.

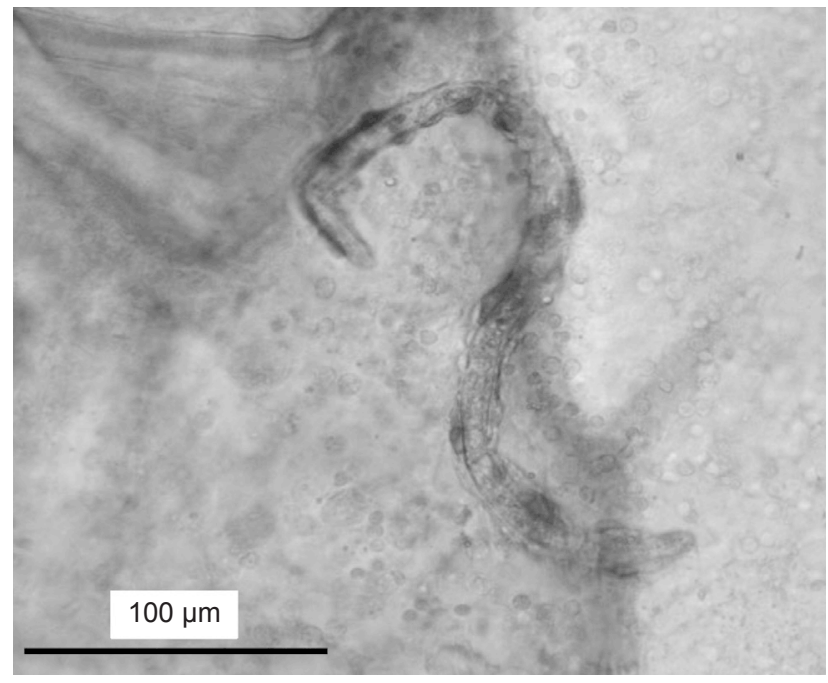

Fig. 2. Photomicrograph of a dead and partially calcified larva of Huffmanela huffmani Moravec, 1987 from San Marcos Springs Hyalella sp. about 5 days post exposure.

Hyalella sp. and never in any of the other exposed amphipods. In some cases, dead larvae had begun showing signs of calcification in SMS Hyalella sp. after as little as 4-6 days post exposure. Aside from this presumed immune response by SMS Hyalella sp., the life span of the larva of $H$. huffmani in the amphipod host seems to be limited by the life span of the intermediate host, since numerous larvae were found alive and active 50 days after last exposing their amphipod host to eggs. Individuals of Hyalella spp. were shown to be capable of living for up to 7 months in our laboratory cultures, but it is unlikely that they live past 4 months in the wild (Othman and Pascoe 2001). No larvae of $H$. huffmani were incubated in Hyalella for the duration of the life span of the Hyalella, and there was no evidence of progressive decline in number of live larvae at 9 weeks post exposure in $H$. cf. azteca.

Eggs of $H$. huffmani stored for more than 21 months in a sealed plastic container outside the definitive host

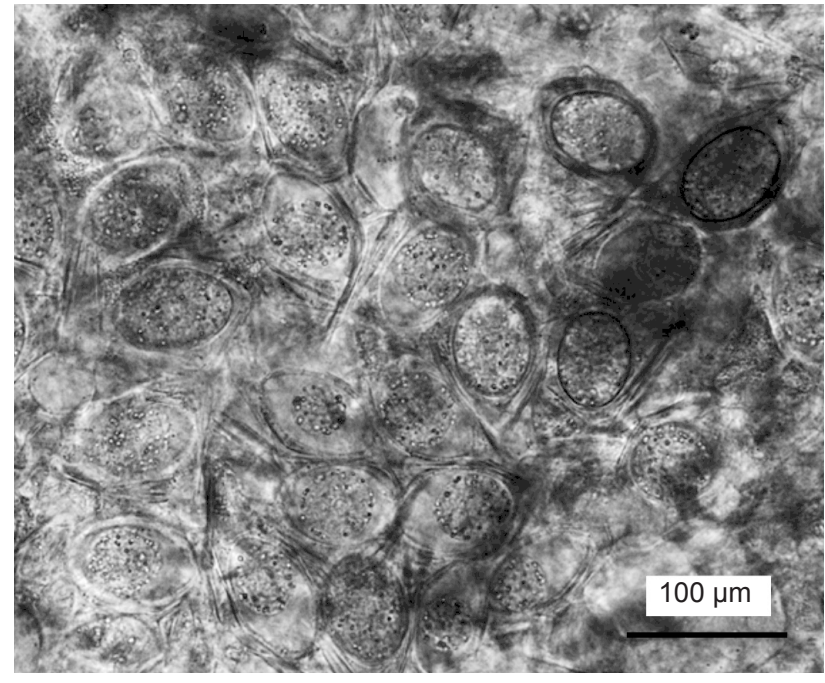

Fig. 3. Photomicrograph of numerous presumably fertilised, freshly deposited eggs of Huffmanela huffmani Moravec, 1987 recovered from an experimentally infected centrarchid incubated for 7.5 months post-infection. Note the apparent lack of shells and polar plugs, and with the contents of eggs enclosed by the the spinose membrane alone.

were still infective to Hyalella, at which point the eggs still showed no sign of decreased infectivity to amphipods. This suggests that eggs released naturally into the environment could remain viable for well over two years and still be infective to amphipods.

None of the experimental fish incubated for less than 4.5 months post exposure showed any signs of infection. Of 20 fish that had been incubated for at least 4.5 months after being fed experimentally infected amphipods (that had incubated for $5+$ days post exposure), $70 \%$ showed evidence of infection. Most of these fish were only lightly infected, with increasing evidence of infection as the incubation duration of the definitive host progressed. The first confirmed deposition of apparently fertilised eggs was not until after 7.5 months of incubation post exposure (Fig. 3). 

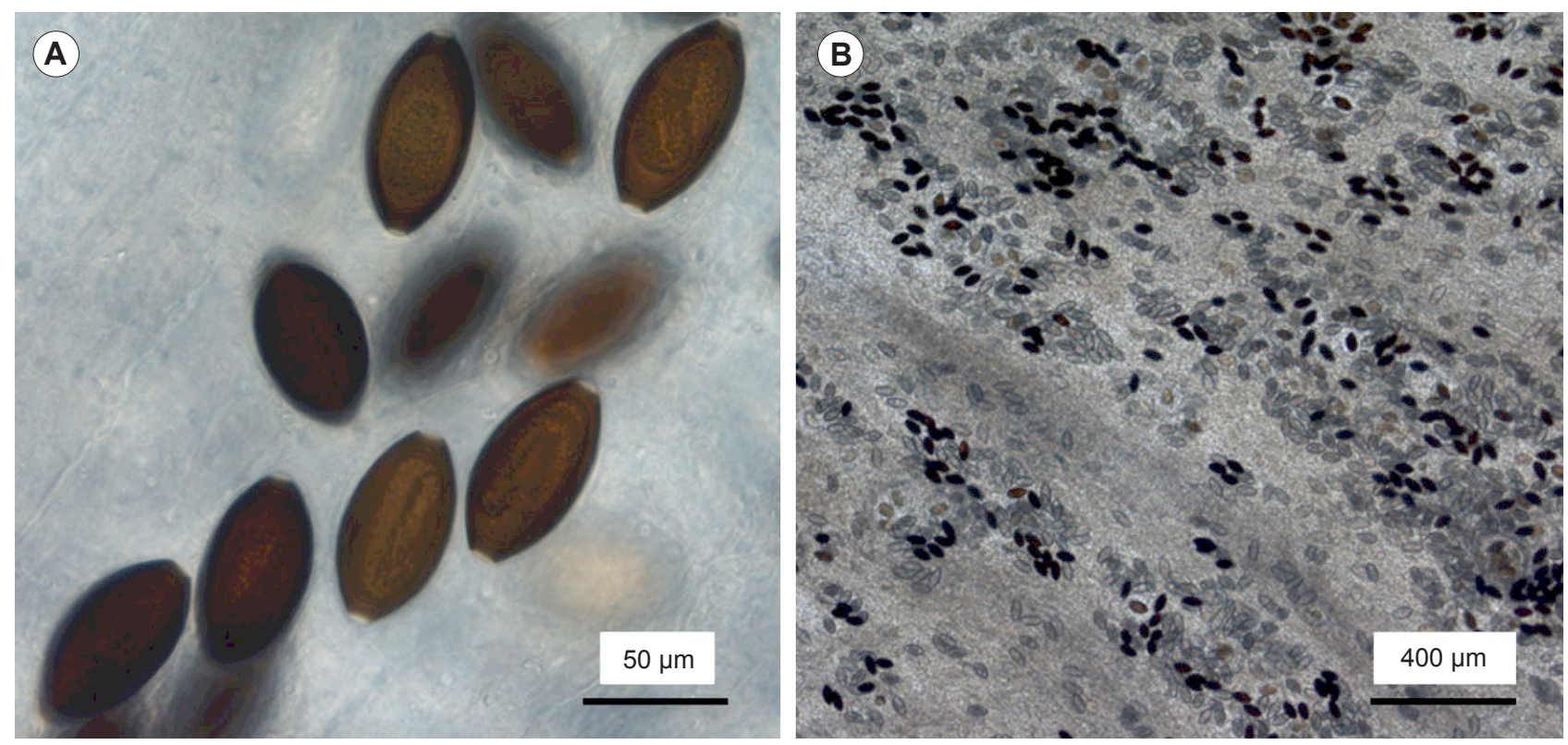

Fig. 4. Eggs of Huffmanela huffmani Moravec, 1987 at various stages of development recovered from experimentally infected centrarchids incubated for 11.5 months post-infection. A - eggs showing evidence of larvation and having fully formed shells and visible polar plugs; B - lower resolution photomicrographs of swim bladder tissue contrasting darker larvated eggs with lighter, more recently deposited eggs.
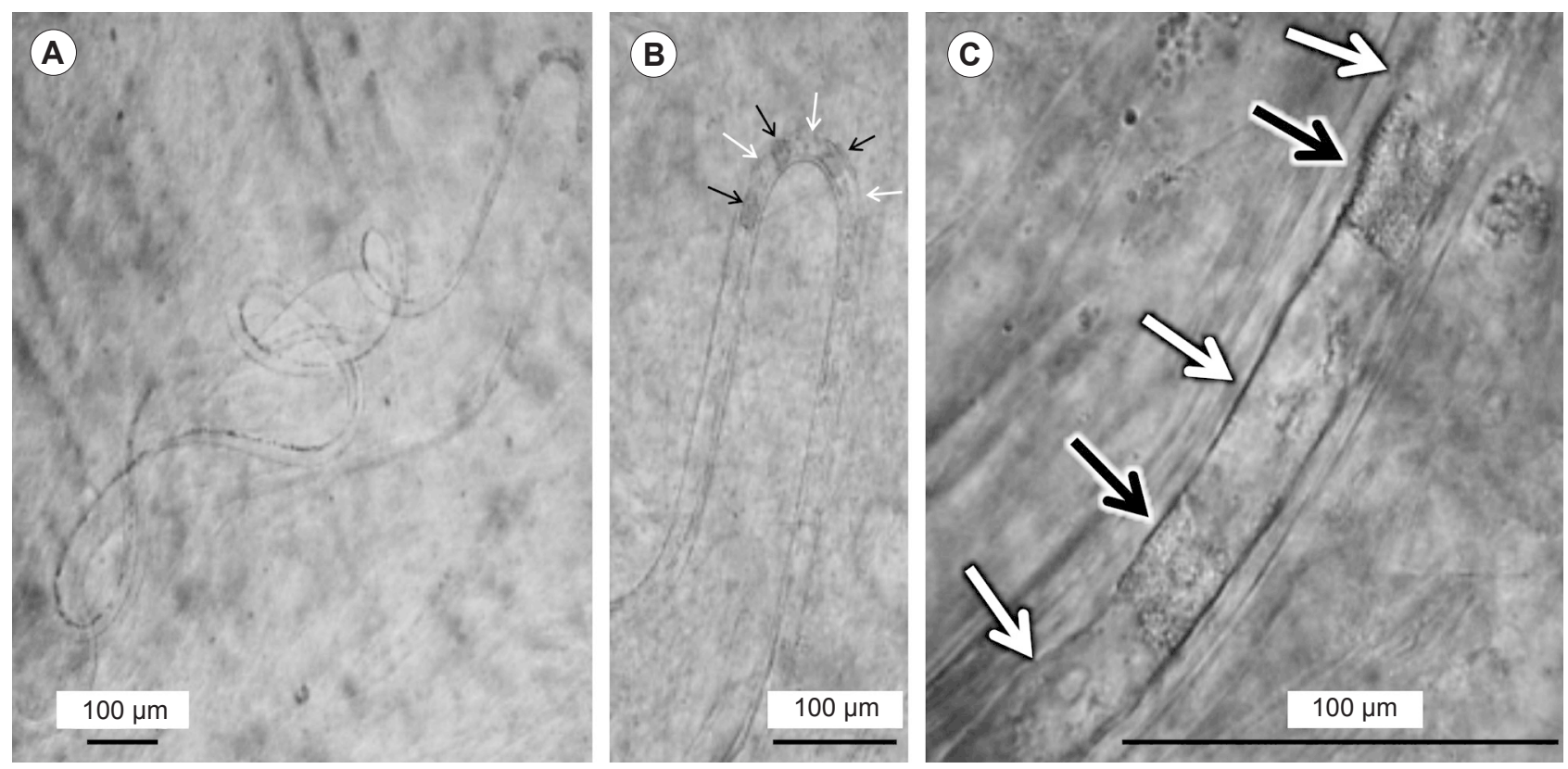

Fig. 5. Huffmanela huffmani Moravec, 1987 recovered from the swim bladder of a fish experimentally exposed to eggs of $H$. huffmani 6.5 months ago. A - gross view entire worm; $\mathbf{B}$ - view of stichosome showing alternation of dark and light stichocytes typical of Huffmanela spp.; C - view of stichosome showing visible stichocyte nuclei and alternating dark (black arrows) and light (white arrows) stichocytes.

However, it was not until after 9 months of incubation that the intensity of infection with eggs in experimentally infected fish appeared to be as heavy as infections observed in the wild; however, none of these eggs were larvated at 9 months. Partially larvated eggs were first observed after 10.5 months of incubation. Fully larvated eggs (Fig. 4) were not observed until 11.5 months post-exposure of the definitive host. Only experimental eggs from fish incubated for at least 11.5 months post infection were able to in- fect Hyalella amphipods, thus experimentally completing the life cycle and overlapping one full generation with the next in captivity. Interestingly, numerous adults (Fig. 5) were observed in fish incubated for up through 9 months, but no adults could be found in infected fish examined at 10.5 months post exposure. This suggests that all the adults had naturally expired at about 10 months of age, since no additional infected amphipods had been fed to the fish after the initial exposure. Infection results are presented in 
Table 8. Results of feeding amphipods experimentally infected with larvae of Huffmanela huffmani Moravec, 1987 to centrarchids.

\begin{tabular}{|c|c|c|c|c|}
\hline Amphipod taxon & $\begin{array}{l}\text { Amphipods } \\
\text { fed out (n) }\end{array}$ & $\begin{array}{l}\text { Duration of incubation } \\
\text { in fish (months) }\end{array}$ & $\begin{array}{l}\text { Infected } \\
(\mathrm{Y} / \mathrm{N}=1 / 0)\end{array}$ & Comments \\
\hline SMS Hyalella sp. & 3 & 4.5 & 1 & $2 \mathrm{~mm}$ piece of posterior of 1 subadult female \\
\hline SMS Hyalella sp. & 4 & 5 & 1 & 3 worms $500 \times 12 \mu \mathrm{m}$; probably $\mathrm{L}_{3}$ or $\mathrm{L}_{4}$ \\
\hline SMS Hyalella sp. & 3 & 6.5 & 1 & 3 adult worms $600 \times 25 \mu \mathrm{m}$ \\
\hline SMS Hyalella sp. & 3 & 7.5 & 1 & Early stage eggs lacking eggs shells found in swim bladder tissue \\
\hline SMS Hyalella sp. & 6 & 7.5 & 1 & One unembryonated egg \\
\hline SMS Hyalella sp. & 8 & 7.5 & 1 & Anterior section of one adult (based on morphometry) \\
\hline SMS Hyalella sp. & 5 & 7.5 & 1 & One young adult male \\
\hline SMS Hyalella sp. & 9 & 7.5 & 1 & 10000 of freshly laid unembryonated eggs; numerous adults \\
\hline Hyalella cf. azteca & 7 & 8.75 & 1 & $\begin{array}{l}10000 \text { of freshly laid eggs (unshelled); } 10 \text { of active adults; }<1 \% \text { eggs partial- } \\
\text { ly larvated }\end{array}$ \\
\hline Hyalella cf. azteca & 9 & 10.5 & 1 & $\begin{array}{l}10000 \text { of partially larvated eggs, eggs had shells indicating they were more } \\
\text { advanced in development }\end{array}$ \\
\hline SMS Hyalella sp. & 5 & 12 & 1 & 10000 of eggs; many fully larvated \\
\hline SMS Hyalella sp. & 21 & 12 & 1 & 10000 of eggs; many fully larvated \\
\hline Hyalella cf. azteca & 21 & 12 & 1 & $\begin{array}{l}100000 \text { of eggs, many fully larvated; intensity approaching that of wild- } \\
\text { caught fish }\end{array}$ \\
\hline
\end{tabular}

SMS - San Marcos Springs.

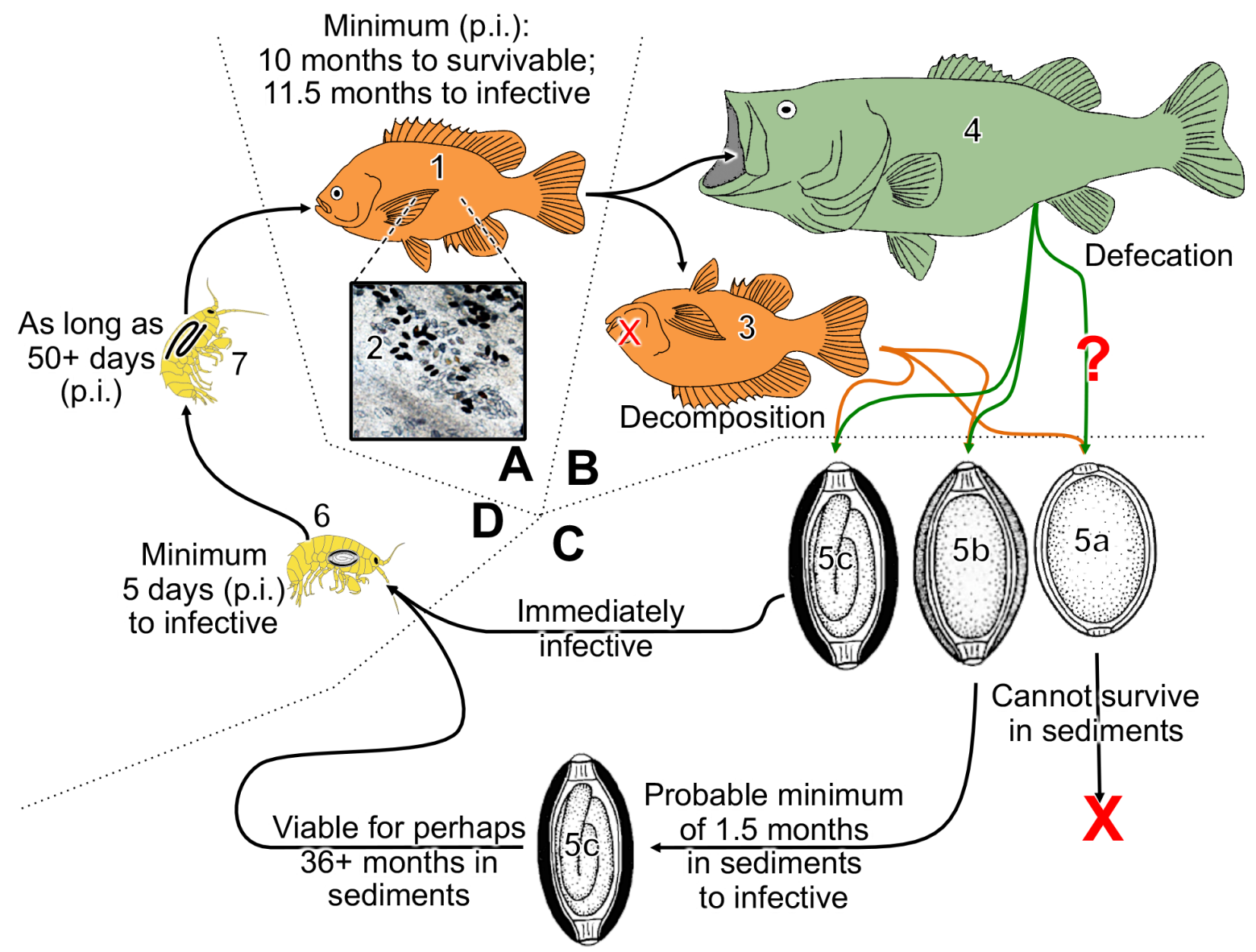

Fig. 6. Diagram showing steps in the life cycle of Huffmanela huffmani Moravec, 1987 (not to scale). A - adults lay eggs in definitive host; at least 7.5 months must pass between ingestion of viable larva and the appearance of fertilised eggs in the host swim bladder, but eggs do not become fully larvated and infective to amphipods until 11.5 months post infection (p.i.): $\mathbf{1}$ - centrarchid definitive host; $\mathbf{2}$ - photomicrograph of swim bladder tissue showing eggs in various stages of development; $\mathbf{B}$ - release of eggs from definitive host: $\mathbf{3}$ - definitive host dies and decomposes to release eggs; $\mathbf{4}$ - definitive host is consumed by piscivorous fish and viable eggs with sufficiently developed shells pass out in faeces; $\mathbf{C}$ - eggs free in sediments: $\mathbf{5 a}$ - young eggs $(<10$ months p.i.) with inadequately developed shells will not survive in environment or passage through piscivore gastrointestinal (GI) tract; $\mathbf{5 b}$ - unlarvated eggs old enough to have fully developed egg shells (>10 months p.i.) can survive in environment and through GI tract of piscivore, but are uninfective to amphipods until they become fully larvated while in sediments; $\mathbf{5 c}$ - fully larvated eggs ( $\geq 11.5$ months p.i.) are immediately infective to amphipods and are still infective to amphipods after $36+$ months in sediments; D - fully larvated eggs ingested by amphipod: 6 - larvae hatch and migrate to hemocoel where they must remain for at least 5 days p.i. before being infective to definitive host; 7 - larva in hemocoel of amphipod and infective to centrarchid. Life cycle can be completed in a theoretical minimum of 12 months, but can probably take longer than 36 months. 


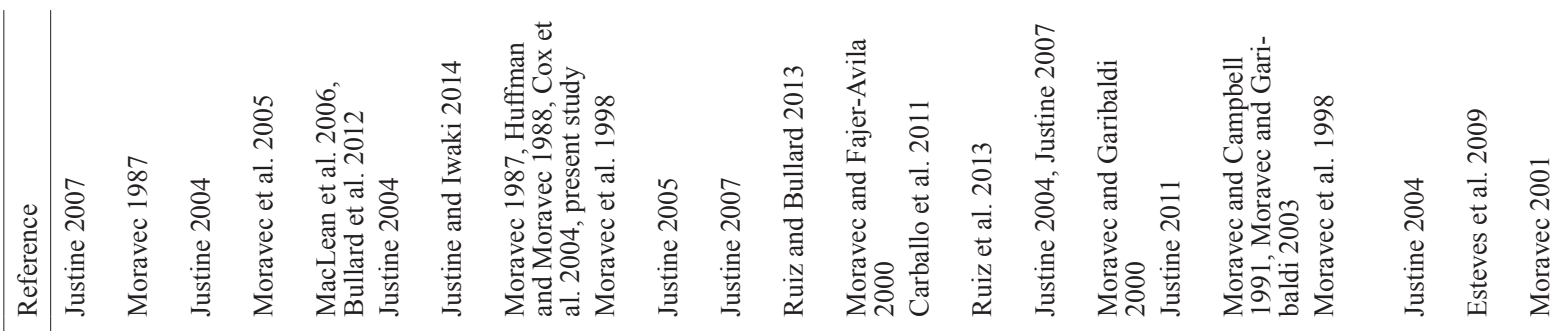

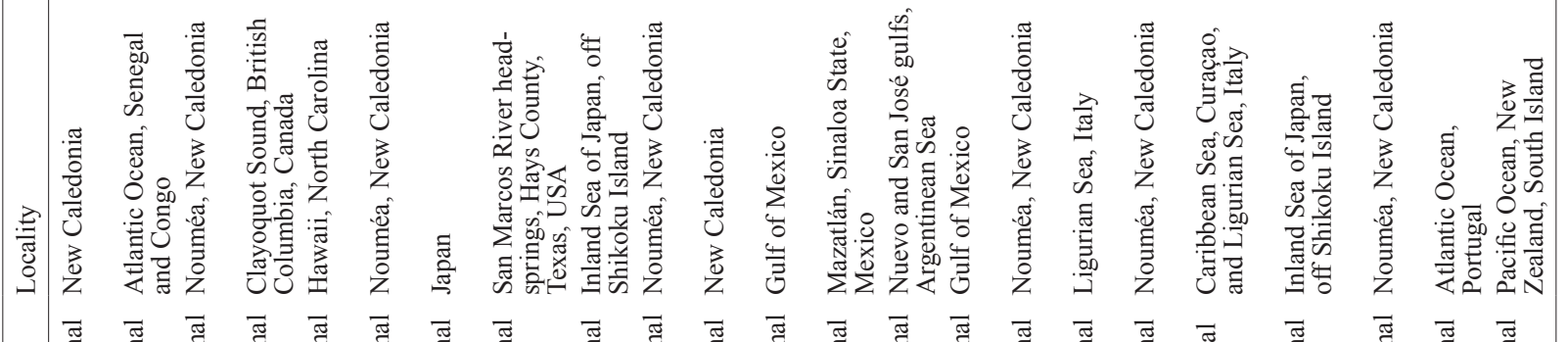

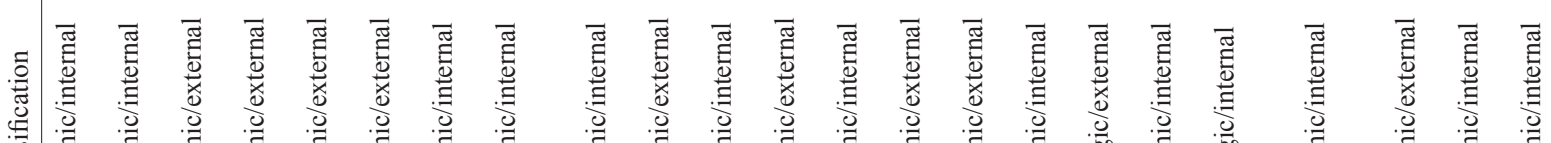

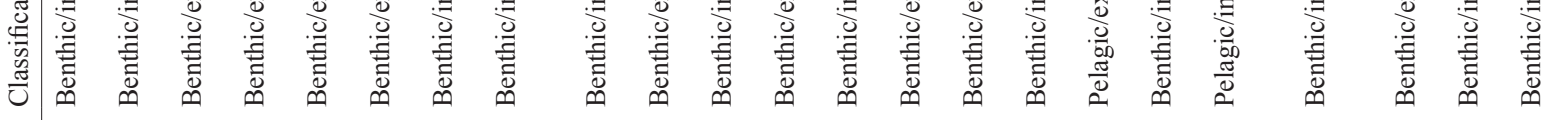

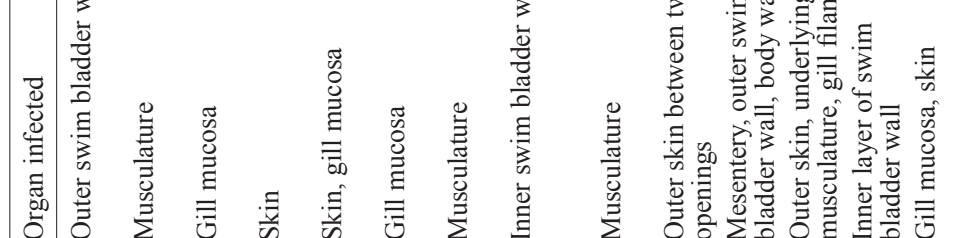

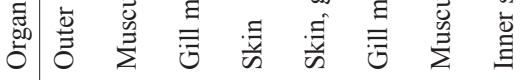

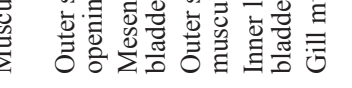

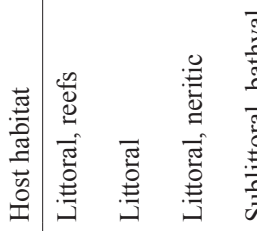

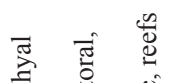

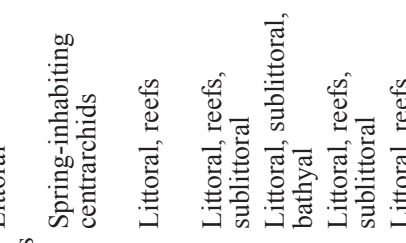

喜 离

$\stackrel{n}{=}$

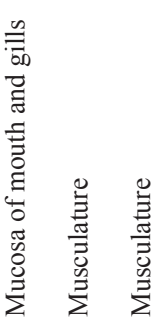


greater detail in Table 8 and Fig. 6 is a summary of what is now known of the life cycle of $H$. huffmani.

\section{Relationship between definitive host diet and location of egg deposition for Huffmanela spp.}

A survey of the literature revealed that Huffmanela spp. have been reported from 18 families of marine fish and one family of freshwater fishes (Table 9). The organ of egg deposition for species of Huffmanela (Table 9) appeared to be somewhat predictable by the habitat of the host (Table 5). Of the 20 benthic definitive host species reported in the literature, $60 \%$ were parasitised by a Huffmanela species that lays eggs in an internal tissue, whereas, $50 \%$ of the two reported pelagic host species were parasitised by a species of Huffmanela which lays eggs in a surface tissue.

\section{DISSCUSSION}

Nine species of centrarchids from three genera were observed to be susceptible to infection with Huffmanela huffmani (see Cox 1998). However, infection prevalence and mean intensity rating was not evenly or randomly distributed across naturally infected centrarchid species (Michel 1984, Underwood and Dronen 1984, Cox et al. 2004, O’Docharty 2007, present study). This uneven distribution of infection with $H$. huffmani across wild-caught centrarchid taxa was determined not to be a function of physiological host specificity, but rather a function of the feeding niches of the various centrarchid species. Indeed, it would seem that the internal environment of all centrarchids is probably equally hospitable to $H$. huffmani, as is demonstrated by the susceptibility ${ }^{1}$ of Ambloplites rupestris Rafinesque, despite that species being only distantly related to Lepomis Rafinesque and Micropterus Lacepède, which are sister genera (Near et al. 2005). Despite their demonstrated susceptibility, wild-caught centrarchid species that we classified as limnetic invertivores were almost never infected in the wild-caught SMS collections, whereas wild-caught individuals of the more benthic centrarchids that feed on interstitial invertebrates were almost always infected. This is consistent with the conjecture that the intermediate host must be a benthic detritivorous invertebrate, and is further consistent with the observation that the eggs are appreciably denser than water. This conjecture was also well corroborated by the AIC contrast analysis in which the niche model explained, by far, the most variance in infection intensity (AIC weight $=0.943$, Table 7).

Therefore, when infection trials were initiated, only benthic invertebrates thought to be detritivores were tested for susceptibility to infection with eggs of $H$. huffmani. After exposing several invertebrate taxa, only one taxonomic group from the SMR proved to be susceptible - amphipods of the genus Hyalella. All specimens of amphipods belonging to several species of Hyalella (including Hyalella spp. taken from localities where $H$. huffmani does not occur) became infected with larvae of $H$. huffmani when exposed to eggs. It is not surprising that $H$. huffmani uses species of
Hyalella as its intermediate host, since this genus is one of the most abundant invertebrate genera in the SMR headsprings; thus, this is a more evolutionarily stable strategy than requiring a rare organism. The undescribed spring-run endemic Hyalella species (referred to herein as SMS $\mathrm{Hy}$ alella sp.) is restricted to the same geographic distribution as $H$. huffmani, which initially led us to assume that some aspect of host specificity to this particular Hyalella species was responsible for limiting the downstream distribution of $H$. huffmani. However, the distribution of the SMS $H y$ alella sp. does not appear to be limiting the distribution of $H$. huffmani, since multiple other species of Hyalella were also experimentally demonstrated to be capable of serving as functional intermediate hosts. In fact, the only amphipod species which showed any sign of being less suitable was the endemic SMS Hyalella sp., which, presumably, coevolved with $H$. huffmani, but which often killed the larvae shortly after infection. Ultimately, both species of Hyalella that occur in the SMR experimentally transferred heavy infections to the definitive host. However, the greatest intensity of experimental infection was observed in definitive hosts that had been fed infected $H$. cf. azteca, suggesting that the presumably coevolved SMS Hyalella sp. seems to have evolved immune responses to $H$. huffmani that are sufficient to appreciably suppress the transmission of $H$. huffmani infections to the definitive hosts.

Species of Hyalella are widespread in freshwaters, with a cosmopolitan distribution across the Americas, and without a single population reported from a marine environment (Serejo 2004, Witt et al. 2006, Wellborn and Broughton 2008). This observation presents an intriguing enigma, that is: "Why is it that $H$. huffmani cannot be found throughout all localities where Hyalella spp. and centrarchids coexist, given that the former can be found co-occurring with centrarchids contiguously throughout much of North America, and $H$. huffmani seems to be able to infect numerous species of Hyalella and centrarchids?"

This makes it difficult to explain the extremely restricted geographic distribution of $H$. huffmani, which is obviously not due to the distributional limits of either its intermediate or definitive hosts. This restricted distribution has been thoroughly documented by a prior study on the distribution of H. huffmani (Cox et al. 2004) and corroborated by the present study. Both studies determined that the farthest downstream point where $H$. huffmani can be found is in the proximity of John J. Stokes San Marcos River City Park (ca 7 river km; $29^{\circ} 52^{\prime} 09^{\prime \prime} \mathrm{N}$; $97^{\circ} 55^{\prime} 43^{\prime \prime} \mathrm{W}$ ) which is close to the downstream extent of the physicochemically stable spring-run waters (Groeger et al. 1997). Because the remainder of the SMR has abundant Hyalella cf. azteca co-occurring with centrarchids, this leads us to the conclusion that the distribution of $H$. huffmani is limited by factors of water physicochemistry.

It is curious that the intermediate host in the life cycle of this marine relict is an exclusively freshwater taxon (Serejo 2004), with all species of the genus Hyalella being found in

${ }^{1}$ Based on unpublished accounts from several Ambloplites rupestris wild-caught from the San Marcos River and examined in parasitology laboratory exercises at Texas State University. 
freshwaters in the Americas. However, the family in which Hyalella is contained (Dogielinotidae Gurjanova) is itself contained in the superfamily Talitroidea Rafinesque, which is a highly diverse group of amphipods containing terrestrial, semi-terrestrial, freshwater and marine species (Serejo 2004). The nearest family to the Dogielinotidae appears to be Hyalidae Bulycheva, which is a talitroid amphipod family that has numerous species with a circumpolar distribution in littoral and intertidal marine environments (Serejo 2004). Therefore, it is possible that talitroids are serving as the intermediate hosts of at least some of the other species of Huffmanela. However, though many of the definitive hosts of marine species of Huffmanela have a diet consisting of benthic invertebrates, the majority of these hosts are not restricted to just littoral and intertidal habitats.

The successful infection of Gammarus sp., though very low in intensity, suggests that some marine Huffmanela may use species of Gammaridea as intermediate hosts. This suborder is extremely diverse and occurs in numerous benthic habitats across the oceans of the world (Raupach et al. 2015). However, the two species of marine Huffmanela with strictly pelagic blue-water definitive hosts (Moravec and Campbell 1991, Moravec and Garibaldi 2000) are paradoxical, because these fishes are unlikely to come into contact with any benthic invertebrates. With the eggs of $H$. huffmani being appreciably denser than water (including hyper-saline water at $45 \mathrm{ppt}$ ), it is difficult to imagine how the eggs of these parasites of pelagic species, assuming their eggs are also denser than water, ever become consumed by a susceptible intermediate host that could then possibly be later consumed by the pelagic definitive host species. One pelagic definitive-host species, Xiphias gladius Linnaeus, is almost exclusively piscivorous on other pelagic fishes (Palko et al. 1981), which suggests the possibility of a second intermediate or paratenic host in the life cycle of Huffmanela paronai Moravec et Garibaldi, 2000.

The epipelagic host fishes in the family Exocoetidae are perhaps the most curious of all described host fishes of Huffmanela, as they are never found in benthic waters and feed almost exclusively on zooplankton (Casazza and Ross 2008), thus eliminating the possibility of a second intermediate host fish that transports the larvae of Huffmanela from the benthos to the definitive host. Aside from these two species, it is highly likely that the intermediate hosts in the life cycle of the other marine Huffmanela species are benthic invertebrates. If the host specificity of Huffmanela spp. is at all conserved at the first intermediate host level, then all Huffmanela spp. are probably using amphipods as intermediate hosts and most likely gammarideans.

It appears that the definitive host is crucial to the larvation of eggs of $H$. huffmani. Freshly laid $\mathrm{F}_{1}$ eggs that had not yet formed a shell inside the spinose membrane were placed in a sealed container filled with artesian water and were kept thermally stable in a water bath of artesian water at $22^{\circ} \mathrm{C}$. None of these eggs larvated and all soon began to decay. However, eggs which had already developed a shell successfully larvated while incubating in water. These observations suggest that eggs cannot survive or larvate out-

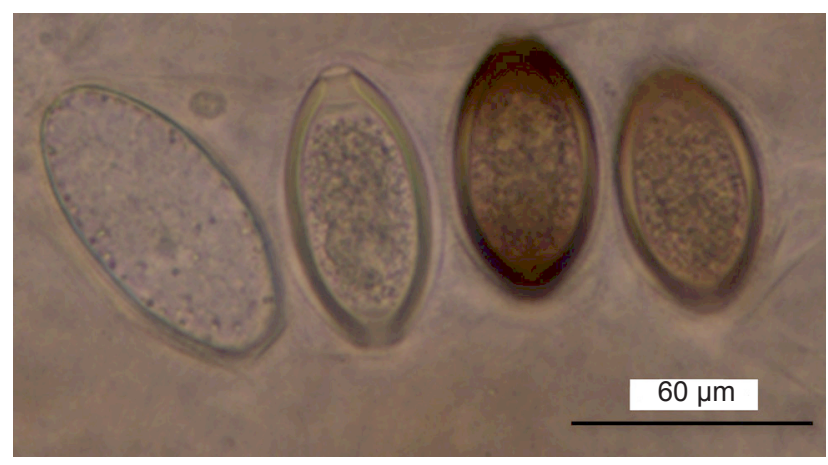

Fig. 7. Eggs of Huffmanela huffmani Moravec, 1987 from a wild caught centrarchid showing gradient of development early in embryogenesis. Left most egg has contents contained solely inside spinose membrane and is therefore thought to have been laid recently. Egg second from left has developed egg shell and polar plugs indicating it as laid some time ago. The two right most eggs show evidence of darkening shells and embryogenesis indicating they were earliest of the four eggs to be laid.

side of the host until they have formed a shell (examples of developmental stages of eggs shown in Fig. 7).

Based on the observation that (1) eggs collected from wild-caught fish are able to survive at least 21 months without a noticeable drop in vitality and (2) eggs are not larvated and infective until approximately 4 months after being laid, it is likely that eggs of $H$. huffmani cannot infect an intermediate host and thus advance the life cycle for at least one year after the fish first becomes infected, but can remain infective for several years after the eggs have been laid. However, it is very unlikely that the minimum life cycle time would be realised in nature, i.e. an egg would be available for consumption by an amphipod as soon as it is fully larvated, and that that amphipod would then be eaten by a centrarchid 5 days post infection.

Therefore, the typical life cycle time would probably be much longer than the one year theoretical minimum observed experimentally. Because it is not yet known how long eggs can survive, it is impossible to estimate a functional generation time; however, given our results it is almost certain that there is substantial overlap between putative generations. Therefore, the possibility for cross-generational gene flow and a lack of discrete generations is highly likely. Based on these findings it is likely that the average generation time is several years, with the majority of each individual's life span spent as an egg.

The prepatent period of $H$. huffmani in the intermediate host appears to be very short, while quite long in the definitive host. Amphipods that had been incubated with larvae of $H$. huffmani for only 5 days successfully transferred infection to the definitive host, even though no development was observed in the larvae until they had incubated in the intermediate host for at least 7 days. Despite the requirement of only modest developmental changes in the intermediate host before $H$. huffmani becomes infective to the definitive host, all evidence available at this time suggests that the amphipod host is very likely an obligate intermediate host, and that the life cycle cannot be completed directly. 
The prepatent period in the definitive host appears to be relatively long for a trichinelloid nematode, as most trichinelloid species for which the life cycle is known usually have a prepatent period around three months (Moravec et al. 1998, Køie and Nylund 2001). Huffmanela huffmani is remarkable in that it appears that the prepatent period is at least 7.5 months at $22^{\circ} \mathrm{C}$ as no eggs were observed until after 7.5 months of incubation and high intensities of eggs were not observed until after nine months of incubation. After egg deposition, larvation appears to take about five months, as the first nearly larvated eggs were not recovered from experimentally infected fish until five months after the first egg deposition was observed. Because this is the first life cycle of species of Huffmanela to be understood, it is not known if a long prepatent period is a conserved trait across any of the other Huffmanela spp.

According to Anderson (2000), trichinelloids always infect the 'final' (= definitive) host in the $\mathrm{L}_{1}$ stage even if a sojourn in an intermediate host (e.g. earthworms) is necessary for larvae to become infective. However, the larval morphogenesis in trichinelloids remains practically unknown, and data on the morphology of individual larval stages are almost absent. Generally, trichinelloid firststage larvae $\left(\mathrm{L}_{1}\right)$ have a stylet, which may also be present in some other stages and adults (Anderson 2000), and their posterior body end is widely rounded, with a subterminal anus. Description and illustration of the first-stage larva of $H$. huffmani expressed from the larvated egg (F.M. and D.G.H. - unpubl. data in Moravec 2001) and also its photomicrograph provided by Cox et al. (2004) show clearly that it is a typical trichinelloid first-stage larva. As in capillariids, no moulting of larvae of $H$. huffmani was observed inside the egg capsule. On the basis of experimental studies and data from the literature, Shlikas (1978) concluded that it is a common feature of all aphasmid nematodes that their larvae do not moult within the eggshells. However, as mentioned by Moravec et al. (1987), van Banning (1980) published a photomicrograph of the larva expressed from the egg of 'Capillaria spinosa' (= Huffmanela banningi Moravec, 1987), a histozoic parasite of tonguefish. This clearly indicates that the larva was undergoing its moult and, therefore, it should be considered the second-stage larva. In contrast, Køie and Nylund (2001) concluded that it is the third-stage larva that hatches from the eggs of capillariids. Obviously, more studies would be helpful in resolving this conundrum.

Based on literature data, the life cycles of some capillariid nematodes are direct (homoxenous), without participation of an intermediate host,; whereas those of others are obligately heteroxenous in which the intermediate host is required. In the homoxenous life cycles, all nematode stages $\left(\mathrm{L}_{1}-\mathrm{L}_{5}\right)$ occur in the definitive host during the parasite's development. Sometimes a paratenic host harbouring the $\mathrm{L}_{1}$ may be included, but this is not obligatory for completing the life cycle. On the other hand, in capillariids with known heteroxenous cycles, the first moult of larvae occurs in the intermediate host, so that only the second-stage larvae $\left(\mathrm{L}_{2}\right)$ are infective for the definitive host (Moravec et al. 1987).
The second moult of capillariid larvae in the earthworm intermediate host was observed, e.g. by Shlikas (1967) in Aonchotheca bursata (Freitas et Almeida, 1934) and A. caudinflata (Molin, 1858), both parasites of domestic fowl and some other birds, and by Romashov (1980) in A. erinacei (Rudolphi, 1819), a parasite of the European hedgehog Erinaceus europaeus Linnaeus. According to Shlikas (1967), in contrast to the $\mathrm{L}_{1}$ larvae, the $\mathrm{L}_{2}$ larvae have no stylet (although a stylet was reported by Morehouse 1942 in $\mathrm{L}_{2}$ of $A$. caudinflata) and their body is much less granulated. Taking this into account, the more fully developed larvae of $H$. huffmani obtained from experimentally infected Hyalella spp. (Fig. 1B) apparently represent second-stage $\mathrm{L}_{2}$ larvae, even though no evidence of larval moult was observed, and we detected no increase in larval dimensions while in the intermediate host. These $\mathrm{L}_{2}$ larvae of H. huffmani have no stylet, and none of the loose refractile bodies (reserve granules) that are obvious in freshly hatched $\mathrm{L}_{1}$ are apparent in the $\mathrm{L}_{2}$ larvae.

Unfortunately, very little information about larval morphogenesis and the number of moults in the intermediate host has been provided by the existing life cycle studies of trichinelloids with heteroxenous cycles. Mostly an increase in size of larvae during their development in the intermediate host has been reported. For example, the body length of larval Cystoopsis acipenseris Wagner, 1867 (Cystoopsidae Skryabin, 1923) increases in gammarids from $170 \mu \mathrm{m}$ to about $380 \mu \mathrm{m}$ (Janicki and Rašín 1930); larvae of Paracapillaria philippinensis (Chitwood, Velázquez et Salazar, 1968) in fish intermediate hosts increase from 130-150 $\mu \mathrm{m}$ to 250-300 $\mu \mathrm{m}$ (Cross 1992); larvae of Capillaria gracilis (Bellingham, 1840) in the fish intermediate host increase from $300 \mu \mathrm{m}$ to $700 \mu \mathrm{m}$ (Køie and Nylund 2001); and larvae of Schulmanela petruschewskii (Shulman, 1948) in oligochaetes increase from 240-350 $\mu \mathrm{m}$ to 760-1250 $\mu \mathrm{m}$ (Kutzer and Otte 1966). Because of the substantial growth reported for these larvae and considering the fact that these larvae can survive for at least several months in the intermediate host, Moravec et al. (1987) speculated that probably more than one moult is probably occurring in the intermediate host. In such a case, it could be expected that both $\mathrm{L}_{2}$ and $\mathrm{L}_{3}$ are infective for the definitive host. If larvae of $H$. huffmani in amphipods become infective for the fish host 5 days p.i., as was found in this study, then the infective stage is $\mathrm{L}_{2}$, which is also indicated by the body size of these larvae (much the same as that of $\mathrm{L}_{1}$ ) much like capillariid larvae which have their first moult within about a week of hatching (see Kasparsone 1984).

Crustaceans are rarely found to be the intermediate hosts of trichinelloids. Although Markevich (1951) incidentally mentions gammarids (Amphipoda) to be the intermediate hosts of the capillariid Piscicapillaria tuberculata (von Linstow, 1914), no relevant source for his report was found in the literature. Most data on capillariid life cycles are on species parasitising birds and mammals. Consequently, the most frequently recorded intermediate hosts have been ascertained to be various earthworms and less often other oligochaetes, and occasionally fishes. The only trichinelloid known to utilise crustaceans as intermediate host is 
the above-mentioned Cystoopsis acipenseris (Cystoopsidae), a parasite of the skin of sturgeons, whose intermediate hosts were found to be three species of gammarids (Amphipoda) (Janicki and Rašin 1930). Accordingly, Huffmanela huffmani is another trichinelloid with a crustacean (amphipod) intermediate host.

Acknowledgements. We are thankful to Texas State University for providing supplies, space and equipment; The Meadows Center for Water and the Environment for providing access to Spring Lake and boat/diving support; and the U. S. Fish \& Wildlife Service for providing specimens and resources pertinent to this study through its San Marcos Aquatic Resources Center. We are deeply grateful to Alex Zalmat, Helen Wukasch and Stephen Harding for spending numerous volunteer hours in the lab and field helping with specimen collections. We would also like to thank Lindsay Stricklan for graciously providing access to SCUBA equipment making it possible to get this project off the ground and under water. The views presented herein are those of the authors and do not necessarily represent those of the U.S. Fish and Wildlife Service.

\section{REFERENCES}

Anderson R.C. 2000: Nematode Parasites of Vertebrates: Their Development and Transmission. CABI Publishing, Wallingford, $650 \mathrm{pp}$.

Anderson R.C., Chabaud A.G. Willmott S. 2009: Keys to the Nematode Parasites of Vertebrates: Archival Volume. CABI Publishing, Wallingford, $463 \mathrm{pp}$.

VAN BANNING P. 1980: The occurrence of black spots in the tongue sole, Cynoglossus browni Chabanaud, due to nematode eggs (Capillaria spinosa) previously described in the shark Carcharhinus milberti Muller \& Henle. J. Fish Biol. 17: 305-309.

Bowles D.E., Arsuffi T.L. 1993: Karst aquatic ecosystems of the Edwards Plateau region of central Texas, USA: a consideration of their importance, threats to their existence, and efforts for their conservation. Aquat. Conserv. 3: 317-329.

Bullard S.A., Ruiz C.F., McElwain A., Murray M.J., BoruCINSKA J.D. BenZ G.W. 2012: Huffmanela cf. carcharhini (Nematoda: Trichosomoididae: Huffmanelinae) from skin of a sandbar shark, Carcharhinus plumbeus, in the Pacific Ocean. J. Parasitol. 98: 333-340.

Carballo M.C., Navone G.T. Cremonte F. 2011: Parasites of the silversides Odontesthes smitti and Odontesthes nigricans (Pisces: Atherinopsidae) from Argentinean Patagonia. Comp. Parasitol. 78: 95-103.

Casazza T.L., Ross S.W. 2008: Fishes associated with pelagic Sargassum and open water lacking Sargassum in the Gulf Stream off North Carolina. Fish. Bull. 106: 348-363.

Cox M.K. 1998: The distribution and life cycle of Huffmanela huffmani (Nematoda: Trichosomoididae). MSc. thesis, Southwest Texas State University, San Marcos, 54 pp.

Cox M.K., Huffman D.G. Moravec F. 2004: Observations on the distribution and biology of Huffmanela huffmani (Nematoda: Trichosomoididae). Folia Parasitol. 51: 50-54.

Cross J.H. 1992: Intestinal capillariasis. Clin. Microbiol. Rev. 5: $120-129$.

Diaz P.H., Alexander M.L. 2010: Aquatic macroinvertebrates of a spring-fed ecosystem in Hays County, Texas, USA. Ent. News. 121: 478-486.

Edwards S.W., Arnold C.R. 1961: The caddis flies of the San Marcos River. Tex. J. Sci. 13: 398-415.

Esteves A., Seixas F., Carvalho S., Nazário N., Mendes M. Martins C. 2009: Huffmanela sp. (Nematoda: Trichosomoididae) muscular parasite from Trisopterus luscus captured off the Portuguese coast. Dis. Aquat. Organ. 84: 251-255.

Gibson J.R., Harden S.J., Fries J.N. 2008: Survey and distribution of invertebrates from selected springs of the Edwards Aquifer in Comal and Hays Counties, Texas. Southwest. Nat. 53: $74-84$.

Groeger A.W., Brown P.F., Tietjen T.E. Kelsey T.C. 1997 Water quality of the San Marcos River. Tex. J. Sci. 49: 279-294.

Hasslinger M.A., Schwarzler C. 1980: Blasenwurm der Ratte, Trichosomoides crassicauda: Untersuchungen zu Entwicklung, Ubertragung und Diagnose. Berl. Munch. Tierarztl. Wochenschr. 93: 132-135.

Holsinger J.R., Longley G. 1980: The Subterranean Amphipod Crustacean Funa of an Artesian Well in Texas. Smithsonian Institution Press, Washington D.C., 62 pp.
Huffman D.G., Moravec F. 1988: First description of adult Huffmanela huffmani Moravec, 1987 (Nematoda: Trichosomoididae) from the swim bladder of centrarchid fishes of the upper San Marcos River, central Texas. Folia Parasitol. 35: 227-234.

JANICKI K., RAŠ́́N K. 1930: Bemerkungen über Cystoopsis acipenseri des Wolga-Sterlets, sowie über die Entwicklung dieses Nematoden in Zwischenwirt. Z. Wissenschaft. Zool. 136: 1-37.

Justine J.L. 2004: Three new species of Huffmanela Moravec, 1987 (Nematoda: Trichosomoididae) from the gills of marine fish off New Caledonia. Syst. Parasitol. 59: 29-37.

Justine J.L. 2005: Huffmanela lata $\mathrm{n}$. sp. (Nematoda: Trichosomoididae: Huffmanelinae) from the shark Carcharhinus amblyrhynchos (Elasmobranchii: Carcharhinidae) off New Caledonia. Syst. Parasitol. 61: 181-184.

Justine J.L. 2007: Huffmanela spp. (Nematoda, Trichosomoididae) parasites in coral reef fishes off New Caledonia, with descriptions of $H$. balista n. sp. and H. longa n. sp. Zootaxa 1628: $23-41$.

Justine J.L. 2011: Huffmanela plectropomi n. sp. (Nematoda: Trichosomoididae: Huffmanelinae) from the coral grouper Plectropomus leopardus (Lacépède) off New Caledonia. Syst. Parasitol. 79: 139-143.

Justine J.L., Iwaki T. 2014: Huffmanela hamo sp. n. (Nematoda: Trichosomoididae: Huffmanelinae) from the dagger-tooth pike conger Muraenesox cinereus off Japan. Folia Parasitol. 61: 267-271.

KASPARSONE Z.V. 1984: [New data on the development of the nematode Capillaria corvorum (Rudolphi, 1819) Travassos, 1915 in the organism of Corvus frigilegus L.]. Izv. AN Latv. SSR. 8: 115-117. (In Russian.)

Køie M., Nylund A. 2001: The life-cycle of Capillaria gracilis (Capillariidae), a nematode parasite of gadoid fish. Sarsia 86: 383-387.

Kutzer E., Отте E. 1966: Capillaria petruschewskii (Schulman, 1948): Morphologie, Biologie und pathogene Bedeutung. Z. Parasitenkd. 28: 16-30.

Löwenstein S. 1910: Epithelwucherungen und Papillombildungen der Rattenblase, verursacht durch ein Trichosoma (Tr. crassicauda?). Beitr. Klin. Chirurg. 69: 533-546.

Maclean R.A., Fatzinger M.H., Woolard K.D. Harms C.A. 2006: Clearance of a dermal Huffmanela sp. in a sandbar shark (Carcharhinus plumbeus) using levamisole. Dis. Aquat. Organ. 73: 83.

Markevich A.P. 1951: Parasitic Fauna of Freshwater Fish of the Ukrainian SSR. Publ. House of the USSR Acad. Sci., Kiev, 376 pp.

Michel G.D. 1984: The Biology of Capillaria sp. (Nematoda: Capillariidae) from Swim Bladders of Sunfishes of the Upper San Marcos River. MS thesis, Southwest Texas State University, San Marcos, $59 \mathrm{pp}$.

MoraveC F. 1987: Revision of Capillariid Nematodes (subfamily Capillariinae) Parasitic in Fishes. Studie ČSAV No. 3. Academia, Praha, 144 pp.

Moravec F. 2001: Trichinelloid Nematodes Parasitic in Cold-Blooded Vertebrates. Academia, Praha, 432 pp. 
Moravec F., Campbell B.G. 1991: A new Huffmanela species, H. schouteni sp. n. (Nematoda: Trichosomoididae) from flying fishes in Curaçao. Folia Parasitol. 38: 29-32.

Moravec F., Conboy G.A. Speare D.J. 2005: A new trichosomoidid from the skin of Sebastes spp. (Pisces) from British Columbia, Canada. J. Parasitol. 91: 411-414.

Moravec F., FAJer-Avila E. 2000: Huffmanela mexicana n. sp. (Nematoda: Trichosomoididae) from the marine fish Sphoeroides annulatus in Mexico. J. Parasitol. 86: 1229-1231.

Moravec F., Garibaldi F. 2000: Huffmanela paronai sp. n. (Nematoda: Trichosomoididae), a new parasite from the skin of swordfish Xiphias gladius in the Ligurian Sea (Western Mediterranean). Folia Parasitol. 47: 309-314.

Moravec F., Garibaldi F. 2003: First record of Huffmanela schouteni (Nematoda: Trichosomoididae), a histozoic parasite of flying-fishes, in Europe. Dis. of Aquat. Organ. 57: 173-175.

Moravec F., Koudela B., Ogawa K. Nagasawa K. 1998: Two new Huffmanela species, H. japonica n. sp. and H. shikokuensis n. sp. (Nematoda: Trichosomoididae), from marine fishes in Japan. J. Parasitol. 84: 589-593.

Moravec F., Prokopič J., Shlikas A.V. 1987: The biology of nematodes of the family Capillariidae Neveu-Lemaire, 1936. Folia Parasitol. 34: 39-56.

Morehouse N.F. 1942: Life cycle of Capillaria caudinflata, a nematode parasite of the common fowl. Iowa State College, Ames, Iowa, $133 \mathrm{pp}$

Near T.J., Bolnick D.I., Wainwright P.C. 2005: Fossil calibrations and molecular divergence time estimates in centrarchid fishes (Teleostei: Centrarchidae). Evolution. 59: 1768-1782.

O'Docharty E.M. 2007: Studies on the Life Cycle of Huffmanela huffmani (Nematoda: Trichosomoididae). MS thesis, Texas State University, San Marcos, Texas, 55 pp.

Othman M.S., Pascoe D. 2001: Growth, development and reproduction of Hyalella azteca (Saussure, 1858) in laboratory culture. Crustaceana 74: 171-181.

Palko B.J., Beardsley G.L., Richards W.J. 1981: Synopsis of the biology of the swordfish, Xiphias gladius Linnaeus. NOAA Tech. Rep. NMFS Circ., 441 pp.

Raupach M.J., Barco A., Steinke D., Beermann J., Laakmann S., Mohrbeck I., Neumann H., Kihara T.C., PointNER K. RADUlOvici A. 2015: The application of DNA barcodes for the identification of marine crustaceans from the North Sea and adjacent regions. PLoS ONE 10: e0139421.
Romashov B.V. 1980: Life cycle of Capillaria erinacei (Nematoda, Capillariidae). Helminthologia 17: 181-189.

Ruiz C.F., Bullard S.A. 2013: Huffmanela markgracei sp. n. (Nematoda: Trichosomoididae) from buccal cavity of Atlantic sharpnose shark, Rhizoprionodon terraenovae (Carcharhiniformes: Carcharhinidae), in the northwestern Gulf of Mexico off Texas. Folia Parasitol. 60: 353-358.

Ruiz C.F., Ray C.L., Cook M., Grace M.A. Bullard S.A. 2013: A new species of Trichosomoididae (Nematoda) from skin of red snapper (Perciformes: Lutjanidae), on the Texas-Louisiana Shelf, Northern Gulf of Mexico. J. Parasitol. 99: 318-326.

SerEJo C.S. 2004: Cladistic revision of talitroidean amphipods (Crustacea, Gammaridea), with a proposal of a new classification. Zool. Scr. 33: 551-586.

Shlikas A.V. 1967: [Ontogenesis of the nematodes Capillaria bursata Freitas et Almeida, 1934 and Capillaria caudinflata (Molin, 1858) Travassos, 1915]. Acta Parasitol. Lithuan. 7: 119-130. (In Russian.)

Shlikas A.V. 1978: [Studies on the development of the nematode Trichocephalus leporis Froelich, 1789 in the organism of the definitive host.]. Acta Parasitol. Lithuan. 16: 81-87. (In Russian.)

Thomas L.J. 1924: Studies on the life history of Trichosomoides crassicauda (Bellingham). J. Parasitol. 10: 105-136.

TISI 2015: Redbreast Sunfish (Lepomis auritus). Texas Invasive Species Institute, Huntsville, Texas.

Underwood H.T., Dronen N.O. 1984: Endohelminths of fishes from the upper San Marcos River, Texas. Southwest. Nat. 29: 377-385.

Wahl D.V., Chapman W.H. 1967: The application of data on the survival of eggs of Trichosomoides crassicauda (Bellingham) to the control of this bladder parasite in laboratory rat colonies. Lab. Anim. Care 17: 386-390.

Wellborn G.A., Broughton R.E. 2008: Diversification on an ecologically constrained adaptive landscape. Mol. Ecol. 17: 2927-2936.

Witt J.S., Threloff D.L. Hebert P.N. 2006: DNA barcoding reveals extraordinary cryptic diversity in an amphipod genus: implications for desert spring conservation. Mol. Ecol. 15: 3073 3082.

Worsham M.L.D., Gibson R., Huffman D.G. 2016: The aquatic annelid fauna of the San Marcos River headsprings, Hays County, Texas. ZooKeys: (in press). 